\title{
Síndrome de burnout en docentes de educación básica de contexto rural
}

\author{
Burnout syndrome in basic education teachers on a rural context
}

Kenia Nohel Loya Chávez

Kenia Noheli Loya Chávez. Secretaría de Educación y Deporte, Chihuahua, México. Es licenciada en Educación Primaria y maestra en Desarrollo Educativo. Ha participado como ponente en eventos como el XIV Congreso Nacional de Investigación Educativa (2017) y en el $5^{\circ}$ Encuentro de Jóvenes Investigadores del Estado de Chihuahua (2017). Se desempeña como docente de primaria en el CREI Ignacio Zaragoza No. 2354. Correo electrónico: kenia.loya@hotmail.com. ORCID: https://orcid.org/0000-00034031-885X.

\begin{abstract}
Resumen
El síndrome de burnout es un padecimiento que afecta la salud física y mental de los trabajadores, es resultado del sometimiento a altos niveles de estrés que generan agotamiento emocional, despersonalización e insatisfacción al logro. La docencia es una de las profesiones más afectadas debido a la constante relación con otras personas. Aunado a esto, el contexto en que laboran es un factor que interviene en el desarrollo del síndrome. Por ello, la presente investigación se realiza bajo un paradigma positivista, con un enfoque cuantitativo de alcance descriptivo, además de un diseño no experimental y transversal. Describe la frecuencia con la que se presenta el síndrome de burnout y los síntomas que manifiestan los docentes de educación básica del contexto rural de algunas regiones del estado de Chihuahua, durante el ciclo 2018-2019. Para ello se aplicó el cuestionario EDO de Uribe (2010) a una muestra censal de 24 docentes de dos comunidades rurales pertenecientes a los municipios de Belisario Domínguez y San Francisco de Borja (corresponden a dos de educación preescolar, quince de primaria y siete de educación secundaria). Los resultados arrojaron la ausencia de este padecimiento, sin embargo, revelan un alto riesgo de presentarlo debido a sus elevados niveles de estrés. Los síntomas que padecen los encuestados en peligro son trastornos de sueño, así como de tipo psicosexual y dolores.
\end{abstract}

Palabras clave: Burnout, docencia y contexto sociocultural. 
in the rural context in some regions of the State of Chihuahua, during the 2018-2019 cycle. To do this, the EDO questionnaire by Uribe (2010) was applied to a census sample of 24 teachers from two rural communities belonging to the municipalities of Belisario Domínguez and San Francisco de Borja (corresponding to two of preschool education, fifteen of primary and seven of secondary education). The results showed the absence of this condition. However, they reveal a high risk of presenting it due to its high levels of stress. The symptoms suffered by those surveyed in danger are sleep disorders, as well as of a psychosexual type, and pain.

Keywords: Burnout, teaching and socio-cultural context.

\section{Problema de estudio}

La globalización, el capitalismo y la competitividad como contexto socioeconómico mundial exigen una permanente transformación y el sometimiento a cambios y exigencias que pueden generar un desequilibrio interno en los trabajadores y con ello un impacto negativo en diferentes ámbitos de la vida personal, social, laboral y en la salud de los mismos. A nivel internacional y local, la preocupación por la salud ha permitido identificar al burnout como uno de los síndromes laborales que afectan a la población mexicana.

La comunidad científica concibe al burnout como "un síndrome de agotamiento emocional, despersonalización y falta de realización personal en el trabajo que puede desarrollarse en aquellas personas cuyo objeto de trabajo son personas en cualquier tipo de actividad" (Gill-Monte, 2005, p. 45). Es por ello que la docencia se reconoce dentro de las profesiones más tendentes a presentarlo.

En el 2017 la OMS identificó a más de 560 millones de personas, a nivel mundial, que sufren trastornos mentales como depresión y ansiedad, apareciendo entre sus múltiples causas el ámbito laboral. En México, el Instituto Nacional de Estadística y Geografía (INEGI, 2018) registró 6,808 defunciones por suicidios a causa de trastornos en la salud mental. Mientras tanto, en Chihuahua, la Comisión de Salud (2018) en su decreto 0756 muestra cifras de 8.5 a 14 suicidios por cada 100 mil habitantes, lo cual posiciona al estado en el tercer lugar de incidencia a nivel nacional. Además, el Instituto Chihuahuense de Salud Mental menciona que la ansiedad es uno de los trastornos mentales más atendidos en consultas y registra a 10,108 personas en tratamiento.

Por otra parte, el Instituto Mexicano del Seguro Social (IMSS) reveló que el 75\% de los mexicanos padece fatiga por estrés laboral e incluso afirman que "el estrés es potencialmente contagioso, ya que estar cerca o visualizar a otras personas en situaciones de estrés puede aumentar los niveles de cortisol del observado" (IMSS, s.f., s.p.). Un estudio realizado por la UNAM acerca del síndrome de burnout hizo evidente que el 100\% de los trabajadores encuestados sufre o ha sufrido estrés, y de ellos $60 \%$ lo ha experimentado en niveles altos (Castillo, 2016). 


\section{ANTECEDENTES}

La revisión de antecedentes descubre que el síndrome de burnout en los docentes es un tema de relevancia actual, tanto que las investigaciones encontradas residen en diversas partes del mundo, España (2009), Perú (2013) y México (2003), en la mayoría de los niveles educativos. En lo que compete al estado de Chihuahua, los estudios se concentran en el nivel superior, por lo que ubicar el presente estudio en docentes de nivel básico y en un contexto específico podría complementar la información que se posee de la salud en el ámbito laboral educativo considerando el entorno.

\section{Pregunta general de inVestigación}

La presencia de burnout en docentes de educación básica afecta directamente a la salud del profesorado e indirectamente a las personas a quienes brinda el servicio, como: alumnos, padres, otros docentes, autoridades e incluso a su propia familia. Sin embargo, existen variables que pueden influir en el desarrollo de este padecimiento, entre ellas el contexto. De acuerdo con lo anterior, surge el siguiente cuestionamiento como guía principal del presente estudio: ¿Cuáles son las características de los docentes de educación básica del contexto rural de algunas regiones del estado de Chihuahua que manifiestan el síndrome de burnout?

\section{Objetivo general}

Describir la frecuencia con la que se presenta el síndrome de burnout y los síntomas que manifiestan los docentes de educación básica del medio rural.

\section{Objetivos específicos}

- Establecer la frecuencia con que se presenta el síndrome de burnout en docentes de educación básica del medio rural.

- Identificar las características de los docentes que padecen burnout.

- Conocer los síntomas que presentan los docentes que padecen síndrome de burnout.

\section{ABORDAJE METOdológICO}

Esta investigación se lleva a cabo bajo el paradigma positivista, que se caracteriza por ser hipotético-deductivo, racionalista y riguroso, además, "pretende confirmar y predecir los fenómenos investigados, buscando regularidades y relaciones causales entre elementos. Esto significa que la meta principal es la construcción y comprobación de teorías" (Hernández, Fernández y Baptista, 2014, p. 6). Siguiendo dicho paradigma, el procesamiento de datos se realiza con un enfoque cuantitativo con un alcance descriptivo y un diseño no experimental y transversal. 
Técnicas e instrumentos

Para la recolección de datos se empleó la técnica de encuesta a través del cuestionario Escala Mexicana de Desgaste Ocupacional (EDO) de Uribe (2010), que mide el nivel de desgaste ocupacional a través de 65 ítems, divididos en dos partes. La primera se compone de 30 enunciados que identifican el nivel de desgaste ocupacional en la vida laboral y considera tres aspectos principales, que son: agotamiento emocional, despersonalización y satisfacción laboral (que refieren a las dimensiones del síndrome de burnout). La segunda parte corresponde a 35 ítems que recuperan los síntomas, once relacionados con el sueño, cuatro hacia lo psicosexual, seis a los gastrointestinales, seis a psiconeuróticos, cinco al dolor, uno a la ansiedad y uno a la depresión. Las respuestas son a través de diferencial semántico de seis espacios.

Muestra

La recolección de datos se realizó durante el ciclo escolar 2018-2019 en el estado de Chihuahua. Se seleccionó una muestra censal, que corresponde a 24 docentes (dos de educación preescolar, quince de primaria y siete de educación secundaria) pertenecientes a dos comunidades rurales de los municipios de Belisario Domínguez y San Francisco de Borja.

\section{MARCo teórico}

Maslow (citado por Huilcapi, Jácome, y Castro, 2017), a través de su teoría psicológica de la motivación, ordena mediante una pirámide las necesidades básicas del ser humano y destaca la salud como una necesidad primaria, un elemento que influye directamente en el comportamiento de los individuos.

La OMS define a la salud como "un estado de completo bienestar físico, mental y social, y no solamente la ausencia de afecciones o enfermedades" (OMS, 1948). Además es un derecho humano y una garantía protegida por la Constitución Política de los Estados Unidos Mexicanos en su artículo 4, que plasma que "toda persona tiene derecho a la protección de la salud” (DOF, 2018, \2). Así también la salud y la productividad mantienen una estrecha relación, tal como lo afirma la Organización Internacional del Trabajo: "Sin salud en el trabajo una persona no puede contribuir a la sociedad y alcanzar el bienestar. Si la salud en el trabajo está amenazada, no existen las bases para lograr el empleo productivo y el desarrollo socioeconómico" (OIT, 2016, p. 2). Una de las enfermedades que afectan a la salud es el estrés.

Selye manejó el término de "estrés" como "la respuesta no específica del cuerpo a cualquier demanda que sobre él se ejerce” (citado por Barrio, García, Ruiz y Arce, 2006, p. 38), es decir, puede surgir de un estímulo interno o externo y se presenta al enfrentarse a una situación sobre la que se tiene un control limitado, y solo desaparece cuando esta se ve superada. 
Actualmente, la palabra "estrés" es cotidianamente relacionada a un efecto negativo, no obstante, esta respuesta puede aparecer incluso en situaciones placenteras, porque en realidad es parte de un proceso natural, debido a que representa la preparación del cuerpo para enfrentarse a las demandas de la vida, por lo que las derivaciones del estrés dependerán de cómo sea orientado, debido a que un mal manejo del mismo podría implicar afectaciones a nivel psicobiológico, es decir en la salud física, mental y/o emocional.

Cuando se aborda el término de "estrés laboral" se refiere a aquel que se desarrolla en el entorno del trabajo, y se define como un proceso dinámico de interacción entre la persona y el ambiente en que se desenvuelve. Dicho proceso inicia cuando un individuo percibe un desequilibrio importante entre las demandas del entorno y su capacidad de respuesta, bajo condiciones en que el fracaso, al hacer frente a dichas demandas, genera consecuencias negativas importantes para la persona (Gil-Monte, 2005).

Los conceptos de "estrés laboral" y "síndrome de burnout", aunque guardan una estrecha relación, han sido erróneamente manejados como sinónimos. La principal diferencia radica en que, en el primero, el proceso podría generar un impacto tanto negativo como positivo, mientras el segundo obligatoriamente tiende a ser negativo.

El término de burnout, según Moriana y Herruzo (2004), surgió en los años setenta cuando Freudenberger lo utilizó para conceptualizar a los síntomas del estrés crónico, y aunque en los ochenta comenzaron a incrementar las investigaciones sobre este tema, fue aceptado por la comunidad científica hasta 1982 cuando Maslach explicó, delimitó y conceptualizó este padecimiento como "una respuesta prolongada a estresores crónicos emocionales e interpersonales relacionados con el trabajo" (citado por Saltijeral y Ramos, 2015, p. 362).

En el ámbito educativo, algunas de las causas que generan el síndrome son:

La presión por concluir el programa educativo, sobrecarga de trabajo y de alumnos que atender, pérdida de prestigio profesional, falta de apoyo por parte de la organización educativa, escaso contacto entre la familia y la escuela, la falta de respeto que muchos alumnos muestran hacia la figura del docente, la necesidad de una mayor preparación para enfrentar los retos que impone el alumnado, rutinas perniciosas que se establecen en los centros, pérdida de condiciones y estabilidad laboral, y sensación de que el trabajo no es suficientemente remunerado, a pesar de laborar, en ocasiones, dos turnos para ganar más dinero [Saltijeral y Ramos, 2015, p. 362].

Por otra parte, según Maslach y Jackson (citados por Saltijeral y Ramos, 2015), el impacto de este síndrome tiene lugar en tres principales dimensiones, que son: el agotamiento emocional, la despersonalización y la baja realización personal.

- Agotamiento emocional. Frente a esta dimensión, el trabajador siente que sus recursos afectivos han sido superados debido al estrés producido por el contacto diario con las personas que reciben directamente su servicio. Esto refiere al agotamiento de energía física y mental, lo que provoca la falta de ideales, esperanza 
y pérdida de interés por el trabajo, pareciendo inútil cualquier esfuerzo. Como acto secuencial afecta a la motivación propia del docente que desarrolla prácticas monótonas y repetitivas, mientras el ambiente de aprendizaje promueve la desmotivación.

- Despersonalización. Se presenta cuando el trabajador desarrolla sentimientos negativos hacia las personas con quienes trabaja, que se traducen en comportamientos y actitudes deshumanizados debido al endurecimiento afectivo. Esto lleva al docente a la confusión en el manejo de situaciones, que pueden presentar maltrato o trato inhumano hacia los alumnos.

- Baja realización personal. También concebida como insatisfacción al logro, es aquella en la que el trabajador evalúa de forma negativa su labor, lo cual altera su autoconcepto, su autoestima, la capacidad de realizar sus funciones y las relaciones con los demás. Es aquí cuando el trabajador se siente descontento consigo mismo e insatisfecho con su desempeño (Savio, 2008). En la docencia, al enseñar sin un compromiso emocional se produce el desapego al magisterio y genera la baja expectativa hacia sus competencias y las de sus alumnos.

Cabe destacar que un trabajador puede sentirse desgastado, despersonalizado o insatisfecho con su trabajo sin sufrir el síndrome de burnout, debido a que este padecimiento es mucho más complejo, para ello debería presentar un deterioro en las tres dimensiones, así como en las áreas de cognición, física, afectiva, actitudinal y conductual.

Como síntomas derivados del síndrome se pueden encontrar: dolores musculares, cefaleas, molestias gastrointestinales, insomnio, cansancio, miedo, absentismo laboral, problemas relacionales, menor dedicación al trabajo, deterioro de rendimiento, irritabilidad, angustia, ansiedad, disminución de concentración y de rendimiento en el trabajo, dificultad para pensar con lógica, poco o nulo disfrute de la actividad laboral, cardiopatías, aumento de la presión arterial, trastornos musculo-esqueléticos, disminución del deseo sexual, disfunciones sexuales, separación/divorcio, accidentes laborales, abandono, entre otros.

\section{RESULTADOS}

En la figura 1 se muestran los niveles de estrés que experimentan los docentes. Un tercio de ellos (33.33\%) manifiesta bajo estrés y $8.33 \%$ lo hace en un nivel regular, mientras que en niveles alarmantes como alto-peligro se encuentra el $58.33 \%$, es decir, la mayoría de ellos, y en el nivel de muy alto los porcentajes corresponden al $0 \%$. Es decir, el $41.66 \%$ se clasifica como sanos o dentro de la normalidad, mientras que el resto se posiciona en riesgo, sin embargo, no se presentan casos de padecimiento del síndrome. 


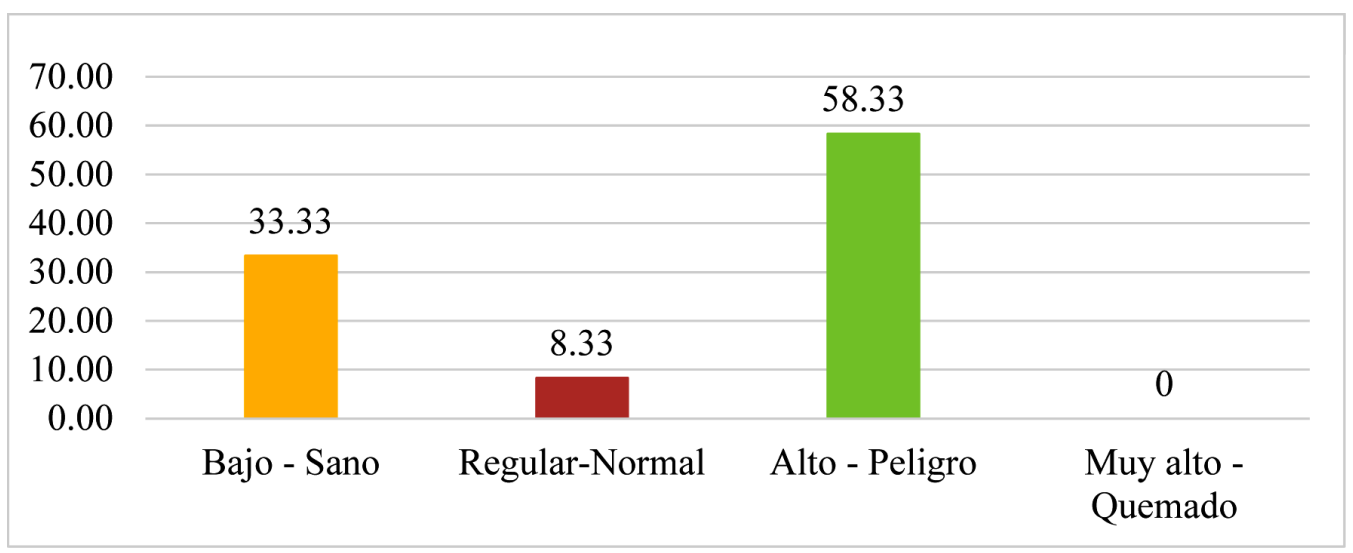

Figura 1. Niveles de estrés laboral en docentes rurales.

Fuente: Elaboración propia.

En la figura 2 se desglosan datos por nivel educativo en el que se labora. En ella se observa que los porcentajes del nivel de estrés bajo y regular pertenecen en su totalidad a docentes que trabajan en primaria, mientras que en el nivel alto $(58.33 \%)$ está compuesto por $8.33 \%$ que corresponde a preescolar, $20.83 \%$ a primaria y $29.17 \%$ a secundaria.

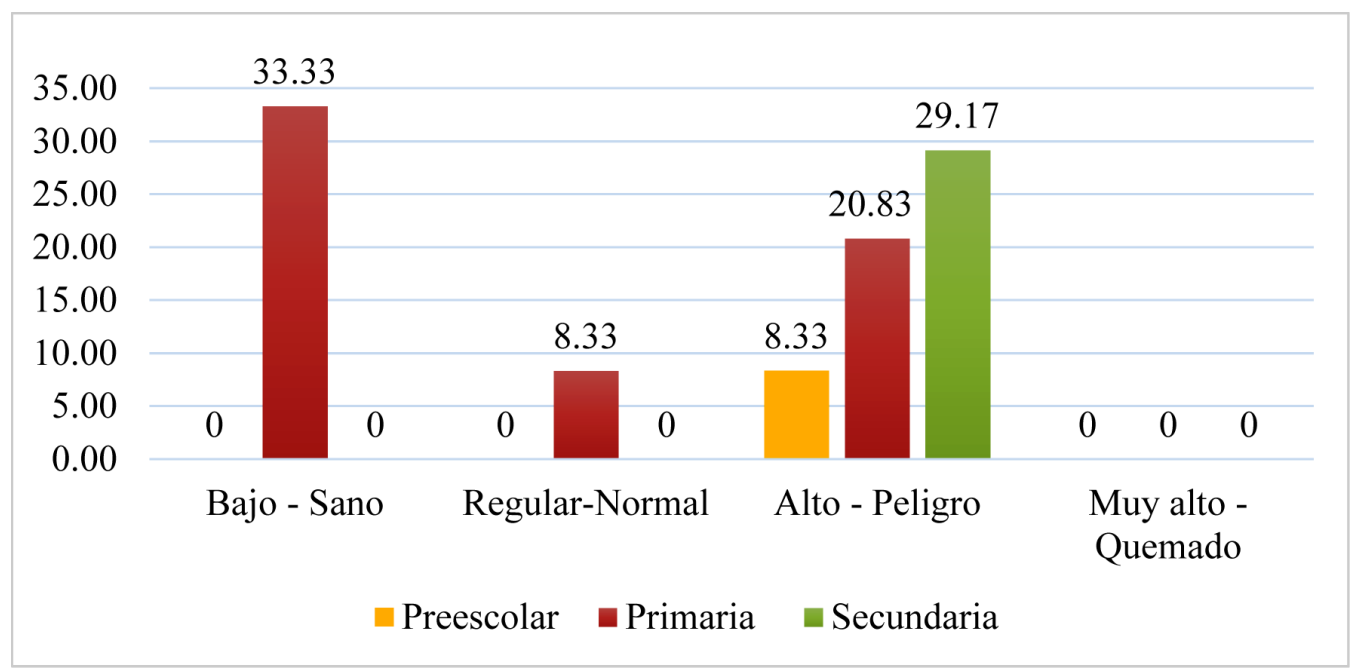

Figura 2. Nivel de estrés y educativo donde laboran los docentes rurales. Fuente: Elaboración propia.

En la figura 3 se consideran las tres dimensiones. Los resultados arrojaron que la más afectada es la de agotamiento emocional con $58.33 \%$, seguida por la despersonalización (16.67\%) y la insatisfacción al logro (16.67\%). 


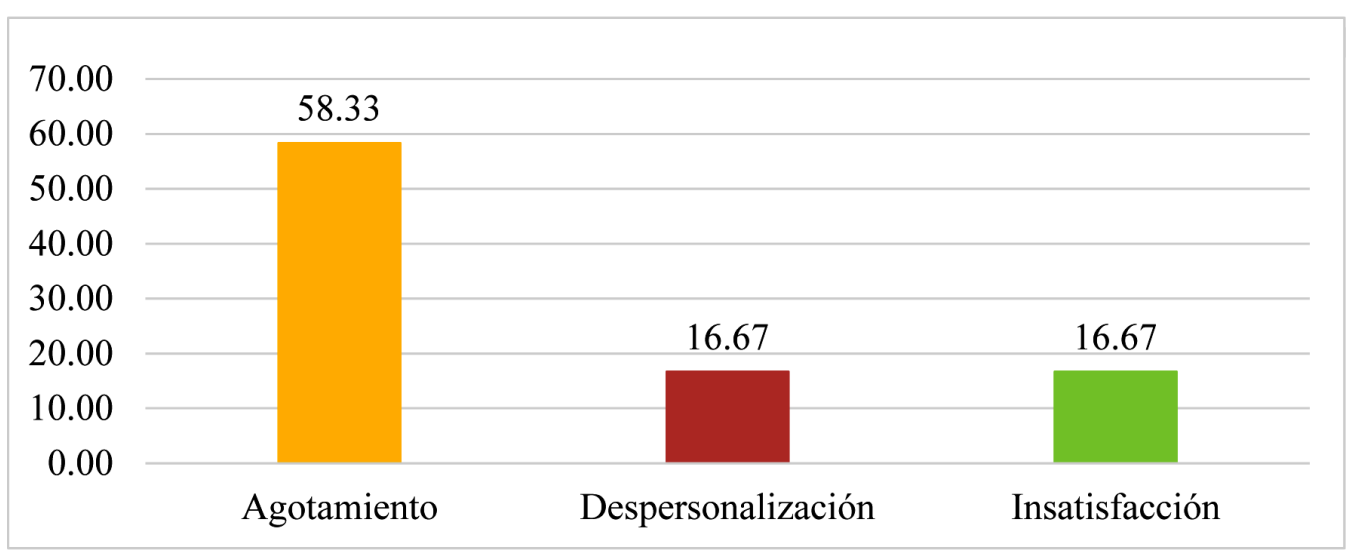

Figura 3. Dimensiones del síndrome de burnout en docentes rurales. Fuente: Elaboración propia.

En la figura 4 se observan aquellos síntomas que pertenecen al trastorno de sueño, siendo 1) sueño en exceso, 2) mala calidad del mismo, 3) despertar bruscamente con gritos o llanto, 4) pesadillas, 5) despertar incapaz de moverse o hablar, 6) problemas respiratorios al dormir (roncar), 7) sonambulismo, 8) insomnio por varios días, 9) periodos de insomnio durante la noche, 10) golpes de sueño repentinos y 11) despertar con taquicardia o tensión. Los que se presentan con mayor frecuencia en los docentes con riesgo de padecer síndrome de burnout, son la mala calidad en el sueño, periodos de insomnios por la noche y golpes de sueño repentinos.

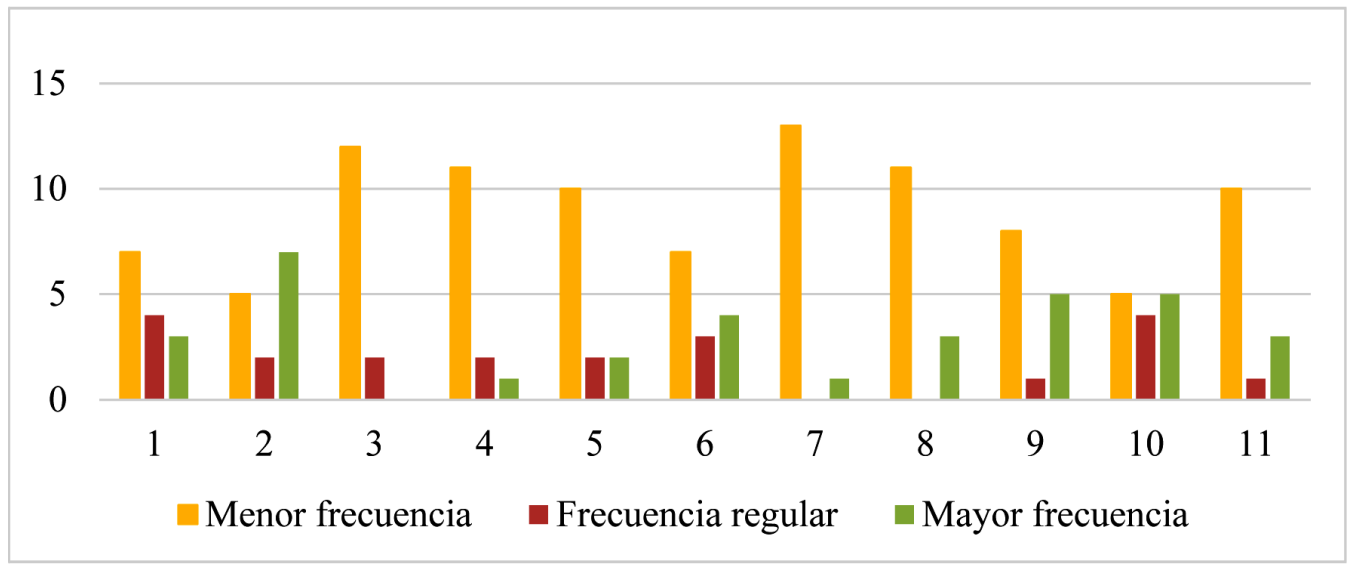

Figura 4. Síntomas del trastorno de sueño.

Fuente: Elaboración propia.

En la figura 5 se observan los síntomas psicosexuales, que son: 1) presentar dolor para desarrollar relaciones sexuales, 2) indiferencia, 3) molestia al orinar y 4) problemas para alcanzar orgasmo. El último es aquel que los docentes experimentan con más frecuencia. 


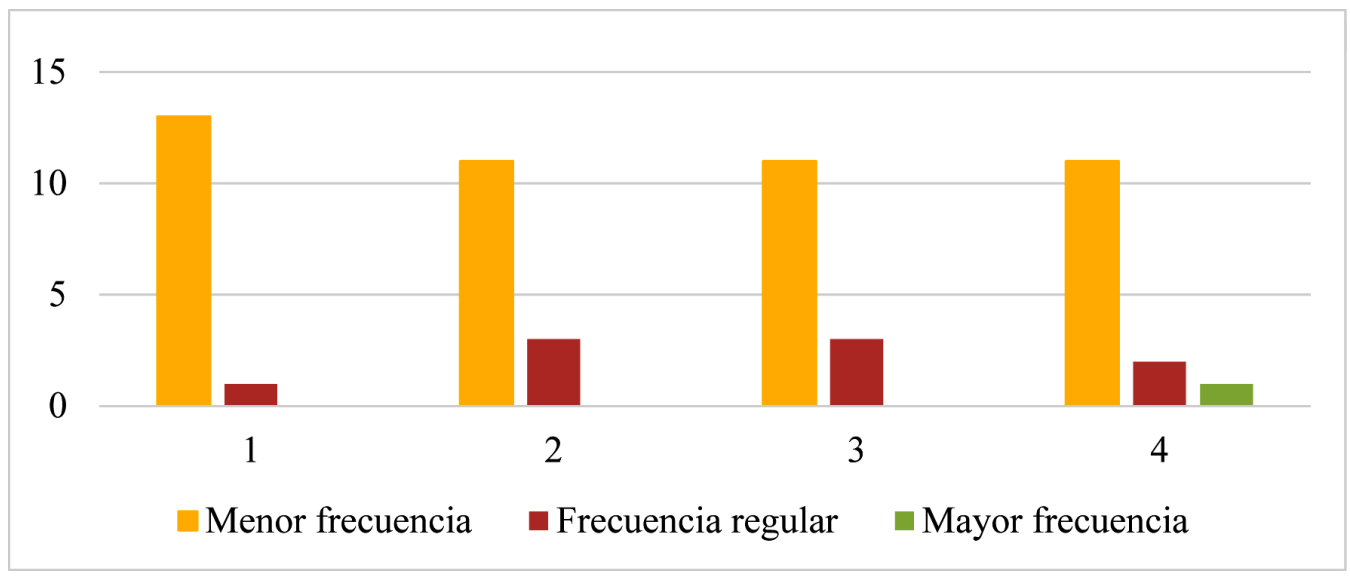

Figura 5. Síntomas psicosexuales.

Fuente: Elaboración propia.

En la figura 6 se observan los síntomas gastrointestinales, que son: 1) dificultad para deglutir, 2) intolerancia a algunos alimentos, 3) vómitos, 4) náuseas, 5) molestia al defecar y 6) diarrea. De estos el de mayor frecuencia es el vómito, aunque también se presentan náuseas, molestia al defecar y diarrea.

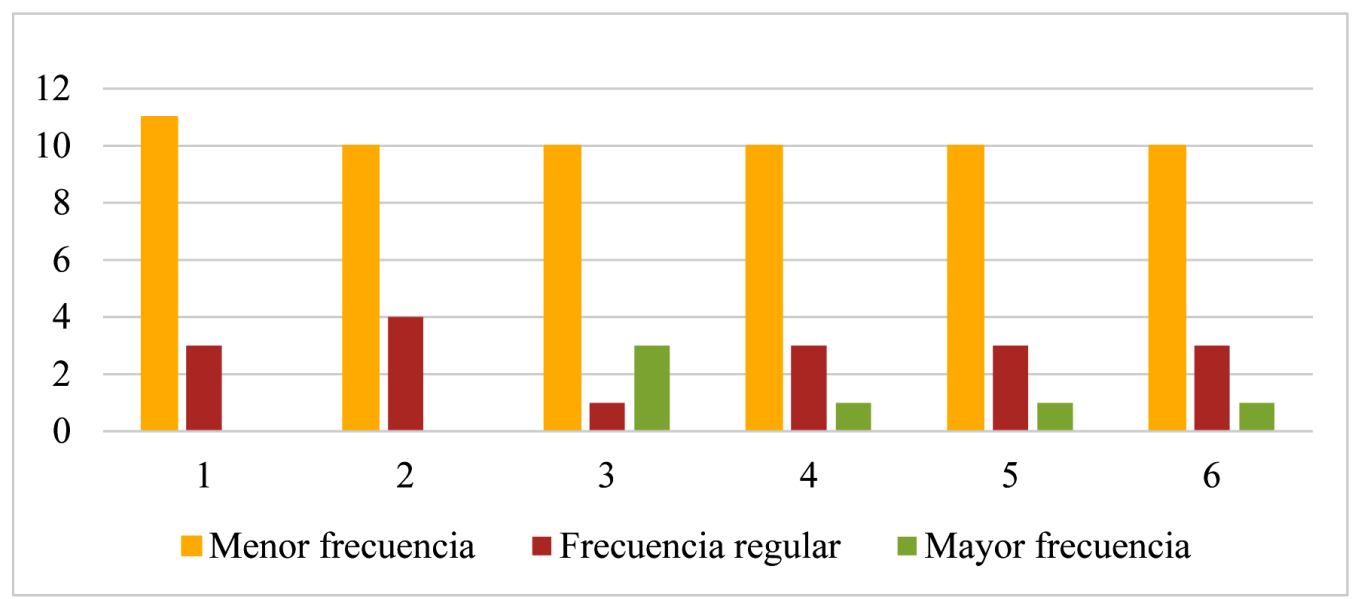

Figura 6. Síntomas gastrointestinales.

Fuente: Elaboración propia.

En la figura 7 se observan los síntomas psiconeuróticos, que son: 1) desmayos, 2) pérdida de sensibilidad, 3) debilidad muscular, 4) sensación de un nudo en la garganta, 5) pérdida de la voz y 6) pérdida del equilibrio. Los que presentan mayor frecuencia son la pérdida de sensibilidad y sensación de nudo en la garganta. 


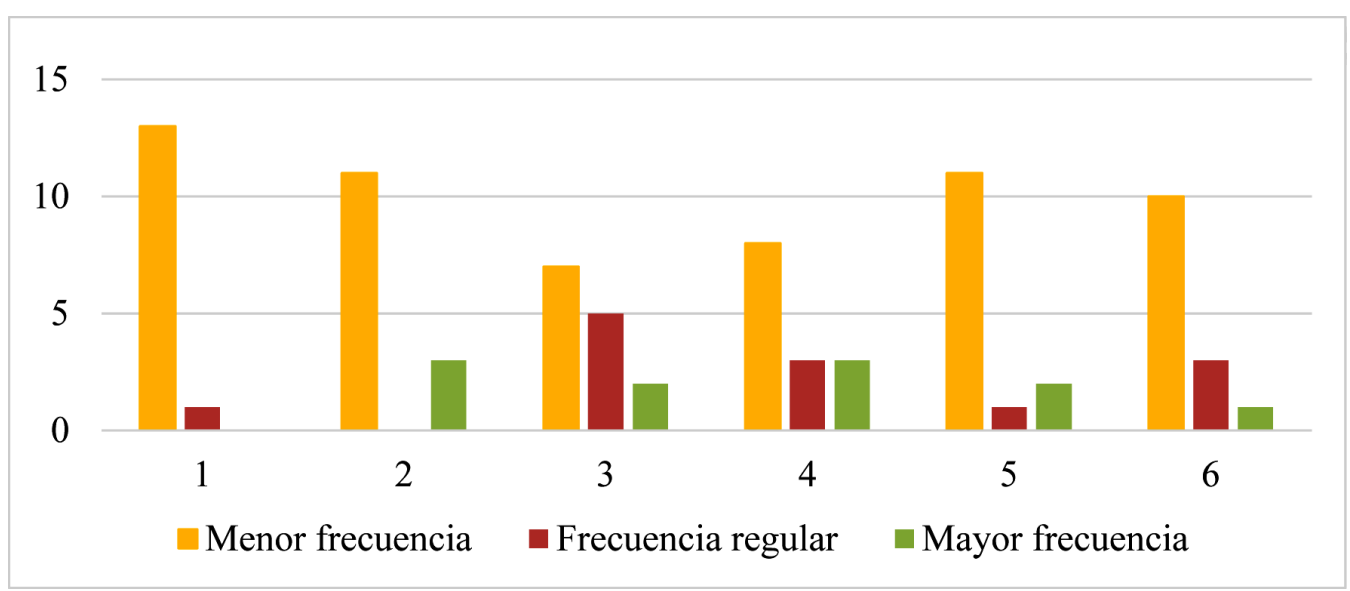

Figura 7. Síntomas psiconeuróticos.

Fuente: Elaboración propia.

En la figura 8 se observan los síntomas que refieren a dolores en cinco partes específicas del cuerpo: 1) cabeza, 2) articulaciones de brazos y piernas, 3) abdomen, 4) espalda o cuello y 5) pecho. Cabe resaltar que, de todos los síntomas revisados previamente, son los dolores los que presentan mayor frecuencia y afectación en los docentes, con incidencia en espalda, cuello y articulaciones.

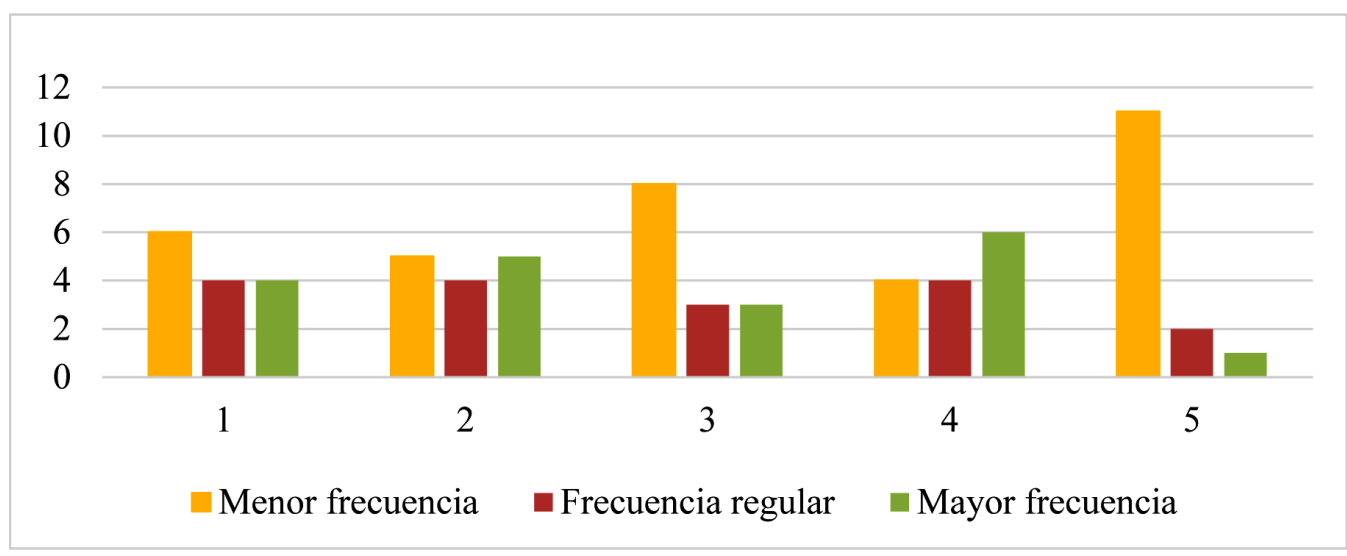

Figura 8. Síntomas de dolor.

Fuente: Elaboración propia.

La figura 9 muestra solo un síntoma de la ansiedad que se refiere a la desesperación. Cinco docentes lo presentan con menor frecuencia, cuatro de manera regular y cinco frecuentemente. 


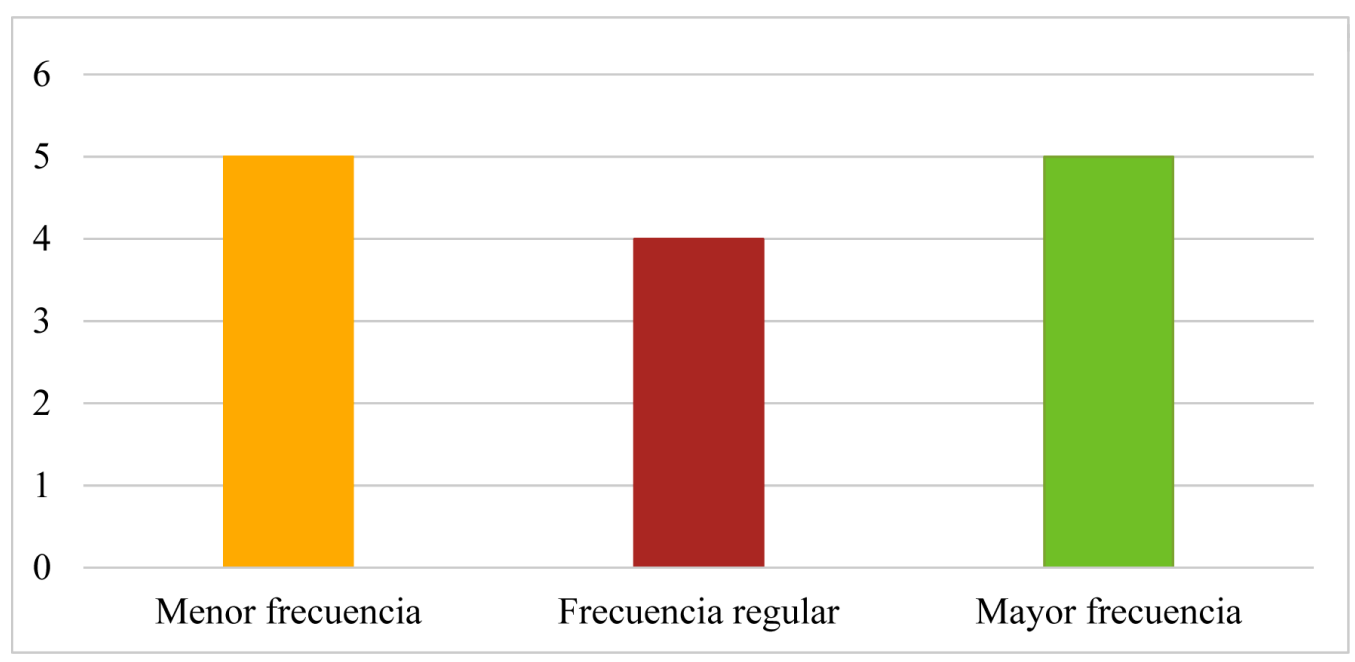

Figura 9. Síntomas de ansiedad.

Fuente: Elaboración propia.

Finalmente, la figura 10 considera la frecuencia del síntoma de depresión. Seis lo presentan menormente, siete regularmente y solo uno frecuentemente.

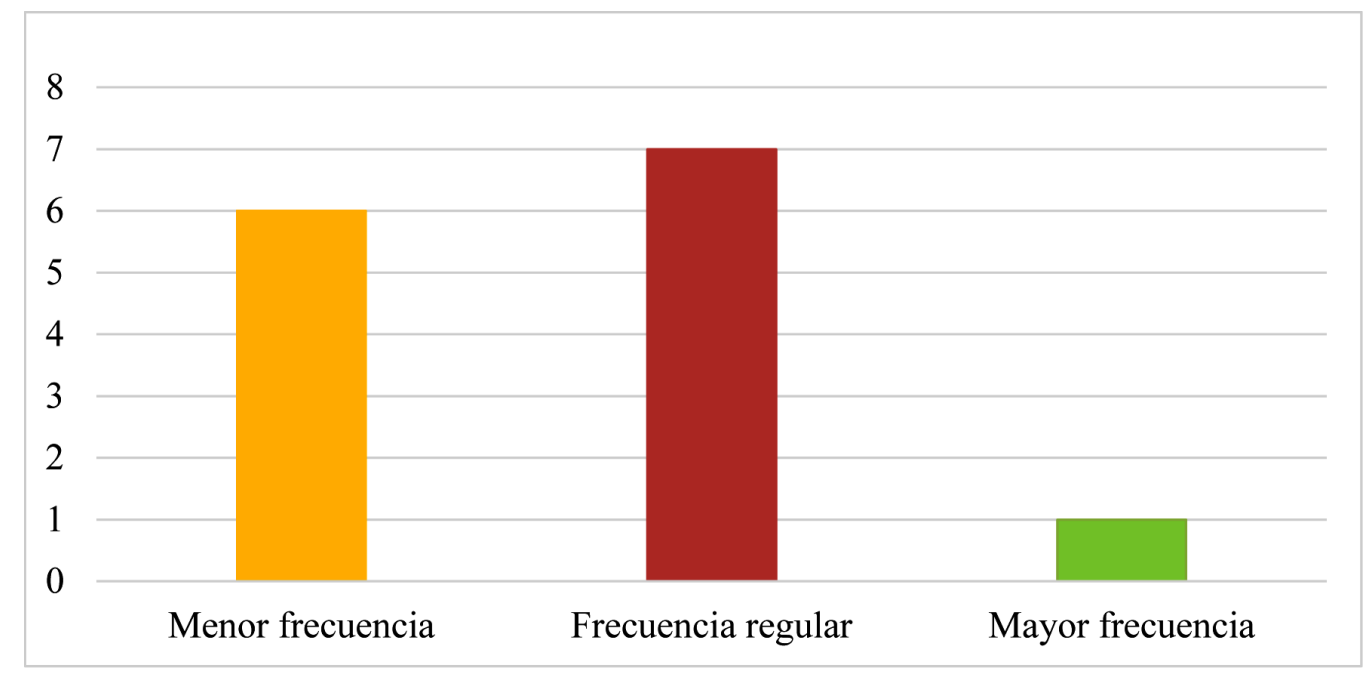

Figura 10. Síntomas de depresión.

Fuente: Elaboración propia.

Variables del síndrome de burnout en docentes

De los docentes en alto riesgo de padecer el síndrome de burnout (58.33\%) se identificaron algunas variables incidentes.

La mayoría de los afectados pertenece al sexo femenino ( $71.42 \%$ ), con una edad promedio de 29 años, el resto corresponde al sexo masculino, con una edad promedio de 32 . En cuanto a su estado civil, se evidencia que los solteros (57.14\%) sufren 
un mayor nivel de estrés que los casados y las cifras reflejan que la mayoría de ellos $(57.15 \%)$ tiene de uno hasta cuatro hijos.

En lo que refiere a su salud, el 64.28\% consume algún tipo de medicamento durante su vida diaria para aliviar síntomas como dolores, ansiedad y padecimientos específicos (autoinmunes o extraños por su baja frecuencia). Además, el 42.85\% no realiza ejercicio y el $14.28 \%$ lo realiza de una a dos horas por semana (moda).

En la distribución de su tiempo, el $21.42 \%$ de los docentes posee de una a siete horas libres por semana, mientras que el mismo porcentaje disfruta de ocho a catorce horas por semana. Es decir, por día descansan desde menos de una hora hasta dos. Asimismo, la mayoría $(78.56 \%$ ) de los docentes tiene de dos a cuatro actividades extra que atender, tales como deportivas, de religión, domésticas, laborales, entre otras.

En la formación profesional, el 71.42\% cuenta únicamente con licenciatura y el $28.57 \%$ tiene un posgrado hasta maestría. En el campo laboral se identifica al 50\% como trabajadores de nivel secundaria, el $35.71 \%$ a primaria y el $14.28 \%$ a preescolar. El puesto que desempeñan casi en su totalidad es la docencia, en ella, el $92.86 \%$ de los docentes cuenta con una antigüedad menor a veinte años de servicio, aunque la moda se posiciona entre los primeros cinco años. El tipo de contrato con el que labora el $64.28 \%$ es base definitiva y atiende a un diverso número de alumnos, ya sea de uno a veinte $(42.85 \%)$, de veintiuno a cuarenta $(28.57 \%)$, de sesenta y uno a ochenta $(7.14 \%)$, de ochenta y uno a cien $(14.28 \%)$ o más de cien $(7.14 \%)$.

\section{CONCLUSIONES}

El síndrome de burnout es un padecimiento que tiene su origen en el trabajo, específicamente surge de las relaciones laborales desarrolladas en el mismo. Esto genera una mayor tendencia en las áreas sociales debido a la naturaleza de estas actividades, que requieren del trato con otras personas, ya sea compañeros o clientes, estos últimos convertidos en estudiantes y padres de familia cuando se trata de la docencia.

A partir de la información recuperada del cuestionario EDO de Uribe se concluye que ninguno de los docentes encuestados presenta síndrome de burnout, sin embargo, más de la mitad de ellos está en riesgo de padecerlo. La dimensión que se encuentra más afectada es la de agotamiento emocional, lo que significa que se sienten cansados por el trabajo. Algunos de los síntomas que más experimentan los docentes en riesgo de burnout son: mala calidad en el sueño, periodos de insomnio en la noche, golpes de sueño repentinos, problemas para alcanzar un orgasmo durante las relaciones sexuales, molestia al defecar, pérdida de sensibilidad, sensación de nudo en la garganta, dolores de espalda, cuello y articulaciones, así como angustia.

Entre los hallazgos de la investigación se identificaron variables comunes entre los docentes con mayor riesgo de padecer el síndrome, como: laborar en educación secundaria, pertenecer al sexo femenino, tener hijos, encontrarse en un rango de edad entre los 34 y los 37 años, tomar medicamentos constantemente, contar con 
un contrato basificado o definitivo y realizar otras dos o más actividades además de su labor docente.

Por lo anterior, se recomienda a los docentes brindar la importancia que este tema amerita, además de hacer un reconocimiento de su salud física y emocional e incluso, de ser necesario, buscar atención especializada para atender áreas vulnerables, para alcanzar el bienestar y con ello una mejor calidad de vida.

Finalmente, una vez evidenciada la situación laboral y de salud de los docentes de educación básica de contexto rural, se deriva una larga lista de posibles líneas de investigación que permitan, en un segundo momento, conocer las causas que generan el síndrome, el impacto dentro del ámbito laboral y personal (mediante un estudio de caso), o bien sería interesante implementar un proyecto de acción que permita prevenir o reducir el riesgo del padecimiento. Todo esto en beneficio del conocimiento y sobre todo de la salud.

\section{REFERENCIAS}

Arias, W., y Jiménez, M. (2013). Síndrome de burnout en docentes de educación básica regular de Arequipa. Arequipa, Perú. Educación. DOI: https://dx.doi.org/10.20511/ pyr2019.v7n3.390.

Aldrete, M., Pando, M., Aranda, C., y Balcázar, N. (2003). Síndrome de burnout en maestros de educación básica, nivel primaria de Guadalajara. Investigación en Salud, 5(1), 0. Recuperado de: https://www.redalyc.org/articulo.oa?id=142/14200103.

Barrio, J., García, M., Ruiz, I., y Arce, A. (2006). El estrés como respuesta. International Journal of Developmental and Educational Psychology, 1(1), 37-48. Recuperado de: https:/ / www.redalyc. org/articulo.oa?id=3498/349832311003.

Castillo, L. (2016). Burnout presente en 60 por ciento de profesionistas mexicanos. Recuperado de: https://www.saludiario.com/Burnout-presente-en-60-por-ciento-de-profesionistasmexicanos/.

DOF [Diario Oficial de la Federación] (2018). ACuERDo por el que se establecen las acciones para el diseño e implementación de la política pública en salud para el otorgamiento de cuidados a largo plazo por las instituciones públicas del Sistema Nacional de Salud. Recuperado de: https://www.dof.gob.mx/nota_detalle.php?codigo $=5533729 \& \mathrm{fec}$ ha $=02 / 08 / 2018$.

Gil-Monte, P. (2005). El sindrome de quemarse por el trabajo (sindrome de burnout): una enfermedad laboral en la sociedad del bienestar. México: Pirámide.

H. Congreso del Estado de Chihuahua (2018). Decreto No. LXV/EXLEY/0756/2018 II P.O. Recuperado de: http://www.congresochihuahua2.gob.mx/biblioteca/dictamenes/ archivosDictamenes/8046.pdf.

Hernández, R., Fernández, C., y Baptista (2014). Metodología de la investigación. México: McGraw-Hill.

Huilcapi, M., Jácome, G. y Castro, G. (2017). Motivación: las teorías y su relación en el ámbito empresarial. Dominio de las Ciencias, 3(2), 311-333. Recuperado de: https:/ / dialnet.unirioja. es $/$ servlet $/$ articulo?codigo $=5889721$.

IMSS [nstituto Mexicano del Seguro Social] (s.f.). Estrés laboral. Recuperado de: http:/ / www. imss.gob.mx/salud-en-linea/estres-laboral. 
INEGI [Instituto Nacional de Estadística y Geografía] (2018). Salud mental. Recuperado de: https://www.inegi.org.mx/temas/salud/.

Merino, E. (2009). Burnout en el profesorado: un estudio comparativo entre profesores de primaria y secundaria. International Journal of Developmental and Educational Psychology, 4(1), 153-159. Recuperado de: https://www.redalyc.org/articulo.oa?id=3498/349832323017.

Moriana, J., y Herruzo, J. (2004). Estrés y burnout en profesores. International Journal of Clinical and Health Psychology, 4(3), 597-621. Recuperado de: https://www.redalyc.org/articulo. oa?id=337/33740309.

OTI [Organización Internacional del Trabajo] (2016). Estrés en el trabajo: un reto colectivo. Turín, Italia: Centro Internacional de Formación de la OIT. Recuperado de: https://www.ilo. org/wcmsp5/groups/public/—ed_protect/—protrav/—safework/documents/publication/wcms_466549.pdf.

OMS [Organización Mundial de la Salud] (1948). ¿Cómo define la OMS la salud? Recuperado de: https://www.who.int/es/about/who-we-are/frequently-asked-questions.

OMS (2017). Día Mundial de la Salud Mental 2017 - La salud mental en el lugar de trabajo. Recuperado de: https://www.who.int/mental_health/es/.

Saltijeral, M., y Ramos, L. (2015). Identificación de estresores laborales y burnout en docentes de una secundaria para trabajadores del Distrito Federal. Salud Mental, 38(5), 361-369. Recuperado de: https://www.redalyc.org/articulo.oa?id=582/58243957008.

Savio, S. (2008). El síndrome del burn out: un proceso de estrés laboral crónico. Revista de Ciencias Sociales Comunicación, 5(1), pp. 121-138. Recuperado de: http://cienciared.com.ar/ ra/usr/3/590/hologramatica08_v1pp121_138.pdf.

Cómo citar este artículo:

Loya Chávez, K. N. (2020). Síndrome de burnout en docentes de educación básica de contexto rural. Revista Electrónica Científica de Investigación Educativa, 5(1), pp. 19-32. doi: doi.org/10.33010/recie.v5i1.955. 